\title{
O mito de Francisco de Vitória: defensor dos direitos dos índios ou patriota espanhol?*
}

\section{The myth of francisco de vitoria: defender of the rights of the indians or spanish patriot?}

\footnotetext{
* Artigo recebido em 29/09/2011

Aprovado em 20/10/2011

1 Professor adjunto de Direito Internacional Público da Universidade do estado do Rio de Janeiro (UERJ), vice-coordenador do Programa de Pós-graduação strictu-sensu em Direito desta universidade, editor-chefe da Revista da Faculdade de Direito da UERJ (RFD), autor de Guerra e cooperação internacional; Hugo Grócio e o direito: o jurista da guerra e da paz e $O$ nascimento do direito internacional. E-mail: borgesmacedo@hotmail.com.
}

\section{Resumo}

O presente texto analisa algumas distorções que a busca por um pai fundador da disciplina de direito internacional provocou quando engendrou o mito de Francisco de Vitória. O teólogo de Salamanca se tornou um defensor do direito dos índios e teria tido uma concepção de direito das gentes bastante moderna. No entanto, Vitória também foi um patriota espanhol e um tomista, duas filiações prejudiciais a essa imagem. Conclui-se que a sua concepção de direito das gentes ainda é antiga, bem distinta da noção atual de direito internacional, e que o autor esposa um direito de intervenção, embora distinto daquele apregoado pela política oficial da Espanha. O método utilizado foi o indutivo, e as fontes primárias foram os próprios textos do autor (documentação bibliográfica). O artigo visa, pois, desmitificar uma ideia muito comum sobre um dos maiores fundadores do direito internacional.

Palavras-chave: Francisco de Vitória. Direito das gentes. Direito natural.

\begin{abstract}
This text analyzes some distortions that the search for a founding father of the discipline of International Law caused when it created the myth of Francisco de Vitoria. The Theologian of Salamanca became a supporter of the right of the Indians and would have had a conception of the Law of the Peoples quite modern. However, Vitoria was also a Spanish patriot and a Thomist, two affiliations harmful to this image. In conclusion, Vitoria's conception of the Law of the Peoples is still ancient and very distinguished from the current notion of International Law; in addition, the author supports a right of intervention, albeit distinct from the one stated by the official policy of Spain. The method used was the inductive and the primary sources were the author's own texts (bibliographic documentation). Hence, the article aims to demystify a very common idea about one of the major founders of International Law.
\end{abstract}

Keywords: Francisco de Vitoria. Law of the peoples. Natural law. 


\section{Introdução}

Do final do século XIII e início do século XIV até o século XVI, o problema da autonomia do jus gentium face ao direito natural não havia progredido desde o jus gentilicum romano. Somente quando a Suma Teológica de Tomás de Aquino termina por suplantar de vez o Livro das Sentenças de Pedro Lombardo, como manual de estudo da Teologia, os teólogos passam a debruçar-se sobre o direito das gentes. A Espanha, em especial, conhece uma renovação tão profunda de interesse pela Escolástica que esse período se torna conhecido como neo-Escolástica, ou Segunda Escolástica. Como ele coincide com as Grandes Navegações, a Espanha experimenta o seu "século de ouro".

A Europa sofria profundas mudanças. Além da descoberta do Novo Mundo, data dessa época a invenção da pólvora e da artilharia, a redescoberta da Antiguidade Clássica, a invenção da imprensa - que disseminou a palavra escrita - e do compasso marítimo, o desenvolvimento da ideia de soberania e o surgimento dos primeiros Estados nacionais. Com tantos progressos tecnológicos - os quais, de fato, alteraram a concepção de mundo -, a Teologia passou a se ocupar também de questões humanas.

Um dos maiores autores desse tempo apresenta-se Francisco de Vitória. Por mais que fosse ortodoxo e fiel ao tomismo, ele vivia num mundo diferente daquele de Santo Tomás e precisou confrontar-se com problemas inéditos; entre outros, a capacidade civil dos índios e o desfazimento da noção de império universal cristão. As Grandes Navegações haviam diminuído o tamanho do planeta e revelado uma multiplicidade de povos pagãos. Pela primeira vez, parecia possível um rei se tornar senhor de todo o mundo. E também, o cristianismo não parecia tão universal assim. Vitória tratou, pois, de atualizar Santo Tomás.

O problema da alma dos índios trazia consigo uma delicada consequência jurídica: povos não cristãos poderiam exercer, de maneira válida, domínio sobre seus territórios. Segundo uma concepção muito divulgada da noção extraída do Antigo Testamento de "terra prometida", diversos canonistas concluíram que, tal como Deus havia presenteado a Palestina para um determinado povo (os judeus), Deus havia doado o mundo inteiro para os cristãos quando da vinda de Cristo. Assim, o credo "correto", o cristianismo, consistiria num requisito para a aquisição válida de um território, e os infiéis poderiam ser legitimamente privados de suas terras. ${ }^{2}$

Cumpre salientar que os cristãos não se mostravam de todo intolerantes. Na metade do século XIII, o Papa Inocêncio IV reconhece que os infiéis podem ser titulares de domínio, posse e jurisdição. ${ }^{3}$ Todavia, os infiéis desse tempo resumiam-se aos muçulmanos, uma civilização tão ou mesmo mais avançada do que a europeia. Como os cristãos, os islâmicos adoravam um Deus único, também professavam uma "religião do livro" e, junto com os judeus, observavam princípios morais que um europeu poderia reconhecer. No relacionamento entre os povos de religião monoteísta, ainda que não vigorasse a paz, existia respeito. Mas o que dizer de crenças que cultuam diversos deuses, inclusive personificações de forças naturais, praticam canibalismo e sacrifícios humanos? A distância em relação às religiões reveladas apresenta-se grande demais. Não há diálogo possível.

Uma vez que o destinatário da tolerância do Pontífice Inocêncio IV era outro, o Islã, não deve causar surpresa a Igreja não aplicar essa posição em relação aos índios. Em 14 de maio de 1493, na famosa bula Inter coetera, o Papa Alexandre VI doou aos reis católicos as "ilhas remotíssimas e as terras firmes" já descobertas por Colombo e "as que se descubram depois", para que possam exercer "plena autoridade e jurisdição" a ocidente de um meridiano ideal conhecido como "linha Alexandrina”, que passava a cem léguas a oeste das ilhas de Açores e Cabo Verde. Em 7 de junho de 1494, o Tratado de Tordesilhas, imbuído desse mesmo espírito de divisão do mundo, modificaria os limites preestabelecidos. ${ }^{4}$

No entanto, mesmo no século XVI, discutia-se a hipótese da bula papal conter autoridade o suficiente para transferir o domínio pleno dessas terras - descobertas e ainda por descobrir (frise-se) - ou haver tão-somente

2 STUMPF, Christoph A. Christian and islamic traditions of public international law. Journal of the History of International Law, Heidelberg, n. 7, p. 71-72, abr. 2005.

3 TIERNEY, Brian. Vitoria and suarez on ius gentium, natural law and custom. In: ___. The nature of customaryl: philosophical, historical and legal perspectives. Cambridge: University of Cambridge, 2004. p. 8.

4 BARTHÉLEMY, Joseph. François de Vitoria. In: PILLET, Antoine. Les fondateurs du droit international. Paris: V. Giard \& E. Brière, 1904. p. 15. 
repartido a autoridade competente entre dois príncipes para a predicação cristã. Esse último caso configuraria o que, em linguagem moderna, denomina-se de "esferas de influência”; o exercício do poder, porém, condicionar-seia à propagação da fé.

Francisco de Vitória iria defender essa última tese. Contudo, ele precisaria sobrepujar interesses quase invencíveis. A teoria rival da doação aparece no Requerimento redigido pela Junta de Burgos de 1512, obra de López Palacios Rubios. Após remontar à Criação do universo, o documento afirma que Deus confiou a São Pedro todos os homens, onde quer que vivessem e sobre qualquer lei, seita ou crença que observassem, para lhes servir de cabeça e senhor, e concedeu o mundo inteiro por seu reino e jurisdição. A seguir, refere-se, de forma expressa, ao ato de Alexandre VI como "doação". Nessas linhas, aparecem todos os principais elementos de uma concepção variante do monismo imperial medieval que estabelece o Sumo Pontífice, em vez do imperador, como o senhor de todo o mundo. Essa teoria havia sido advogada por diversos canonistas, como o Cardeal Hostiensis e Inocêncio III, na decretal Novit Ille, e também por alguns teólogos, em especial, os espanhóis Álvaro Pelayo e Rodrigo Sánchez Arévalo. ${ }^{5}$ A defesa da tese oposta não iria só contrariar a política oficial da Espanha, mas poria o seu expositor em rota de colisão com o próprio papa.

No entanto, séculos mais tarde, essa posição agradaria a sensibilidade de diversos internacionalistas que, a partir da segunda metade do século XIX, procuravam um substituto para Hugo Grotius no papel de fundador do direito internacional. Então, produziu-se uma leitura mitificadora ${ }^{6}$ do teólogo de Salamanca. Alguns dos seus textos foram selecionados, outros ignorados, para, assim, fazer do autor o criador de um conceito inédito de jus gentium e o primeiro defensor dos direitos humanos. Chega a causar estranheza o fato de que James Brown Scott descobre, em algumas passagens do escri-

\footnotetext{
5 VIEJO-XIMÉNEZ, José Miguel. Totus orbis, qui aliquo modo est una republica: Francisco de Vitoria, el derecho de gentes y la expansión atlántica castellana. Revista de Estudios Histórico-Jurídico: sección historia del pensamiento jurídico, Valparaíso, n. 26, p. 359-391, 2004.

6 "Myth is to be defined as a complex of stories - some no doubt fact, and some fantasy - which, for various reasons, human beings regard as demonstrations of the inner meaning of the universe and human life." WATTS, Alan W. Myth and ritual in christianity. London: Thames and Hudson, 1953. p. 7.
}

tor espanhol, a origem do princípio da igualdade jurídica das nações e a noção hodierna de cidadania, ou quando compara o pensamento do teólogo com o do Presidente Lincoln. ${ }^{7}$ Vitória deixa de ser um homem do seu próprio tempo e se torna um mito.

\section{Uma concepção reducionista de vitória}

Vitória ocupava o cargo de prima professor de Teologia em Salamanca, e suas opiniões mereciam respeito. Entretanto, para o dissabor de muitos, ele não endossava o monismo pontifício, nem a guerra contra os índios. Para Vitória, Deus havia distribuído a sua autoridade para todos os povos, não só aos cristãos. Os índios também poderiam possuir terras e exercer soberania, pois se encontravam em "domínio pacífico de suas coisas públicas e privadas. Logo (salvo outro óbice em contrário), devem ser considerados verdadeiros senhores e, nessas circunstâncias, não se pode despojá-los de suas posses" ${ }^{8}$.

Dessa feita, as Relecciones, quando publicadas, só escaparam do Index de obras proibidas por causa da inesperada morte do Papa Sisto V, mas o rei sequer esperou a publicação. Em 1539, o Prior do Convento de Santo Estevão, Domingo de Soto, vespera professor de Teologia e seguidor de Vitória, recebeu uma carta assinada pelo próprio Carlos V que proibia os clérigos desse monastério de expressar posições que fossem de encontro à política ultramarina de Castela. Qualquer manifestação em contrário seria considerada uma ofensa pessoal. ${ }^{9}$ Tratava-se de uma indisposição bastante pontual e limitada a essa questão, porque, em diversos episódios anteriores e mesmo posteriores, o rei manifestou o seu apreço e admiração por Vitória.

A defesa de Vitória de ideias como aquelas atraiu a simpatia de uma literatura, no século XIX, que havia

7 SCOTT, J. B. The spanish origin of international law: Francisco de Vitoria and his law of nations. 2. ed. New Jersey: The Law Book Exchange, 2003. p. 137, 147, 254.

8 "[...] in pacifica possessione rerum et publice et privatim. Ergo omnino (nisi contrarium constet) habendi sunt pro dominis. Neque in dicta causa possessione deturbandi" VITORIA, Francisco de. Obras de Francisco de Vitória: relecciones teologicas. Madrid: Biblioteca de Autores Cristianos, 1960. p. 651.

9 SCOTT, J. B. The spanish origin of international law: Francisco de Vitoria and his law of nations. 2. ed. New Jersey: The Law Book Exchange, 2003. p. 84-85. Nesse livro, o autor reproduz a carta. 
descartado Hugo Grotius e buscava um novo pai para o direito internacional. Em 1860, em um leilão da família De Groot (nome original da forma latinizada "Grotius"), descobre-se, por acaso, o De Jure Praedae Commentarius, obra que Hugo Grócio jamais publicou e que havia desaparecido. Mas em vez de chamar as atenções para o jurista de Delft, as diversas referências aos escolásticos, em especial ao teólogo de Salamanca, serviram de argumentos à disputa da paternidade do direito das gentes. $\mathrm{O}$ próprio prefácio da edição de Gerhard Hamaker salienta a influência decisiva dos espanhóis sobre o holandês. ${ }^{10}$ Já em 1874, sir Thomas Erksine Holland, na sua famosa aula inaugural em Oxford, retira Grócio definitivamente de seu pedestal e apresenta Alberico Gentili como o verdadeiro criador do direito internacional. $\mathrm{O}$ jurista de Delft teria sido apenas o seu discípulo mais importante e, certamente, o mais conhecido. ${ }^{11}$

O pioneirismo, contudo, sempre coube a Vitória, não só por um fator temporal. Outros escolásticos, como Domingos de Soto e Francisco Suárez, por causa de suas obras teológicas e filosóficas, eram, até então, menos desconhecidos do que Vitória. Todavia, as preleções deste último sobre os índios e o poder civil contêm um apelo difícil de ser ignorado, e, rapidamente, o dominicano iria tornar-se a figura central. Os demais hispânicos assumiriam um papel secundário como seguidores do grande maestro. No final do século, a literatura revisionista havia se multiplicado dentro e fora da Espanha. Nesse país, Eduardo de Hinojosa enfatizou, de modo específico, a importância dos teólogos espanhóis. E, na Bélgica, Ernst Nys e o suíço Alphonse Rivier retiram a originalidade de Hugo Grócio:

Quando se afirma que Grócio é o pai do direito natural e o pai do direito das gentes], quer afirmar-se que uma disciplina toda nova saiu de sua cabeça, que ele inventou ou imaginou, por um tipo de intuição divina, as até então desconhecidas regras da guerra, da paz e das relações entre os Estados, entre soberanos, as alianças, as embaixadas? Nada seria mais contrário quer à lógica das coisas, quer à verdade. Uma quantidade de canonistas, de legistas, de publicistas escreveu, desde a Idade

${ }^{10}$ GROTIUS, Hugonis. De jure praedae commentarius. La Haye: Hamaker, 1868. p. 11.

${ }^{11}$ HOLLAND, Thomas E. Alberico Gentili: an inaugural lecture delivered at all souls college. In: STUDIES IN INTERNATIONAL LAW, 7., 1874, Oxford: Clarendom Press, 1898. p. 1-23.
Média, sobre esses temas diversos, bem como sobre assuntos pertencentes ao direito natural. ${ }^{12}$

Lapidou-se uma imagem imaculada e um tanto reducionista do dominicano. Cometeram-se dois exageros: Vitória, tal como seu irmão da ordem Las Casas, havia tornado-se um campeão na defesa dos direitos dos índios e o primeiro a apresentar uma visão moderna de direito internacional. Em outras palavras, o teólogo de Salamanca, segundo esta literatura, teria desenvolvido um conceito de jus gentium até então inédito, que regulamentaria tanto os períodos de guerra como os de paz, e que incidiria sobre Estados soberanos; essa soberania, porém, não se mostraria absoluta, porque haveria um princípio superior que a limita: o totus orbis, uma comunidade internacional e orgânica de todos os povos, que estabeleceria elos de solidariedade com vistas a um bem comum. Essa instância mundial encontrar-se-ia acima das vontades particulares dos Estados, editaria normas internacionais e asseguraria a sua execução. Os próprios Estados funcionariam como órgãos do orbis e valer-se-iam da guerra justa para vindicar injustiças e corrigir enganos, em uma verdadeira antecipação do que, séculos mais tarde, George Scelle chamaria de "desdobramento funcional". 13

Essa concepção, segundo a qual Vitória já teria desenvolvido uma definição moderna de direito internacional, funda-se no seguinte raciocínio: como um legítimo herdeiro de Tomás de Aquino, Vitória compartilha da ideia da solidariedade natural do homem e da consequente naturalidade do Estado; e a sociedade internacio-

\footnotetext{
12 "Est-ce à dire qu'une discipline toute neuve lui ait jailli du cerveau, qu'il ait inventé ou imaginé, par une sorte d'intuition divine, les règles inconnues jusqu'à lui de la guerre, de la paix, des raports entre États, entre souverains, des alliances, des ambassades? Rien ne serait plus contraire, soit à la logique des choses, soit à la verité. Quantité des canonistes, des légistes, des publicistes ont écrit dès le moyen âge sur ces divers sujets, comme aussi sur les sujets appartenant au droit naturel." RIVIER, Alphonse. Note sur la littérature du droit de gens avant la publication du Jus Belli ac Pacis de Grotius (1625). Bruxelles: Académie Royale de Belgique, 1883. Confira também HINOJOSA, Eduardo. Influencia que tuvieron en el Derecho Público de su pátria y singularmente en el Derecho penal los filósofos y teólogos españoles, anteriores a nuestro siglo. Madrid: Reus, 1890 e NYS, Ernest. Le droit de la guerre et les précurseurs de Grotius. Bruxelles et Leipzig: Murquardt, 1882.

${ }^{13}$ Esta corresponde à concepção institucionalista de DELOS, J. T. La société internationale et les principes de droit public. 2. ed. Paris: Pédone, 1950. p. 187-228. Para a tese tradicional mais "pura", confira todo o livro SCOTT, J. B. The spanish origin of international law: Francisco de Vitoria and his law of nations. 2. ed. New Jersey: The Law Book Exchange, 2003.
} 
nal forma uma comunidade assemelhada a um Estado: "E o mundo todo, que de certo modo forma uma república, tem o poder de prescrever, a todos os súditos, leis justas, como são as de direito das gentes." ${ }^{4}$

Da mesma maneira que as repúblicas consistem em agrupamentos naturais formados por indivíduos, existe outra comunidade natural que se compõe de repúblicas, e sobre elas exerce autoridade. Trata-se, segundo essa interpretação, de uma analogia com o próprio Estado; esse seria o significado da oração aliquo modo est una republica. O orbe representa um corpus natural e orgânico, cujos membros são todas as repúblicas. Como qualquer comunidade política, ele promulga verdadeiras leis: “[...] o direito das gentes não tem força somente pelo pacto e convênio dos homens, mas tem verdadeira força de lei". ${ }^{15}$ Assim, o jus gentium independe da vontade dos Estados. O totus orbis constitui uma instância legislativa superior à mera soma de todos os seus membros.

Portanto, a soberania dos Estados resta limitada por um poder superior: o bem comum, motivo pelo qual se constituiu o orbe. A solidariedade natural dos indivíduos torna-se um princípio válido para as relações internacionais. Um evento político que interessa a um Estado afeta a todos. Assim, a justiça desse acontecimento deve ser mensurada de maneira global. "Como cada república é uma parte de todo o mundo e, sobretudo, uma província cristã parte de uma república, se a guerra fosse útil a uma província ou a uma república, mas fosse prejudicial ao mundo ou à cristandade, penso que por esse fato ela seria injusta."16

Contudo, o principal argumento ainda estaria por vir. A literatura que buscou estabelecer Francisco de Vitória como o novo pai do direito internacional encontrou fundamento para a sua pretensão na famosa passagem

\footnotetext{
14 "Habet enim totus orbis, qui aliquo modo est una republica, potestatem ferendi leges aequas et convenientes omnibus, quale sunt in iure gentium." VITORIA, Francisco de. Obras de Francisco de Vitória: relecciones teologicas. Madrid: Biblioteca de Autores Cristianos, 1960. p. 191.

15 "Quod ius gentium non solum habet vim ex pacto et condicto inter homines, sed etiam habet vim legis" VITORIA, Francisco de. Obras de Francisco de Vitória: relecciones teologicas. Madrid: Biblioteca de Autores Cristianos, 1960. p. 191.

16 "Imo cum una respublica sit pars totius orbis et maxime christiana provincia pars totius reipublicae, si bellum utile sit uni provinciae, aut reipublicae, cum damno orbis aut christianitatis, puto eo ipso bellum esse iniustum." VITORIA, Francisco de. Obras de Francisco de Vitória: relecciones teologicas. Madrid: Biblioteca de Autores Cristianos, 1960. p. 168.
}

em que o teólogo de Salamanca retoma a definição de jus gentium de Gaio: “[...] mas o que a razão natural estabeleceu entre todas as gentes se chama direito das gentes"17 (grifo nosso). Vale a pena repetir o supracitado trecho final da definição do jurisconsulto romano: “[...] mas o direito que a razão natural estabeleceu entre todos os homens é uma regra segundo a qual todos observam igualmente e se chama direito das gentes, na medida em que é o direito que todas as nações se servem"18 (grifo nosso). Vitória substitui no texto original a palavra homines por gentes. Consoante essa literatura, não se trata de um pequeno engano por causa de uma citação das Institutas feita de memória pelo autor. A troca teria sido proposital e traria consequências bastante profundas: o sujeito do direito das gentes não mais seriam os homens - o que provoca a confusão desse ramo com o direito natural. Agora, estaria claro: o sujeito seriam os povos.

Esta inovação tem uma importância fundamental. Pois, com a substituição de gentes em lugar de homines, o antigo direito romano, que servia para reger as relações entre todos os homens por todas as partes do mundo, queda convertido num direito que rege as relações dos vários povos considerados como nações, ou melhor, como Estados. ${ }^{19}$

17 "Quod naturalis ratio inter omnes gentes constituit, vocatur ius gentium" VITORIA, Francisco de. Obras de Francisco de Vitória: relecciones teologicas. Madrid: Biblioteca de Autores Cristianos, 1960. p. 191, 706.

${ }^{18}$ O trecho completo: "Em todos os povos que são regidos pelas leis e pelos costumes, serve-se tanto do direito que lhes é próprio, como do direito que é comum a todos os homens. Com efeito, o direito que cada povo estabeleceu para si é próprio à cidade ela mesma; mas o direito que a razão natural estabeleceu entre todos os homens é uma regra segundo a qual todos observam igualmente e se chama direito das gentes, na medida em que é o direito que todas as nações se servem." ("Omnes populi, qui legibus et moribus reguntur, partim suo proprio, partim communi omnium hominum iure utuntur nam quod quisque populus ipse sibi ius constituit, id ipsius proprium civitatis est vocaturque ius civile, quasi ius proprium ipsius civitatis: quod vero naturalis ratio inter omnes homines constituit, id apud omnes peraeque custoditur vocaturque ius gentium, quasi quo iure omnes gentes utuntur.") IUSTINIANUS IMPERATOR. Corpus Iuris Civilis. ed. Krueger e Mommsen. Berlim: Weidmann, 1908. Digesto, 1, 1, 9.

19 "Esta innovación tiene una importancia fundamental. Pues, con la substituición de gentes en lugar de homines, el antiguo derecho romano que servía para regir las relaciones entre todos los hombres por todas las partes del mundo, queda convertido en un derecho que rige las relaciones de los varios pueblos considerados como naciones, o bien, como estados." SCOTT, J. B. Conferencias del presidente del Instituto Americano de Derecho Internacional preparadas en homenaje a la Universidad Mayor de San Marcos. Lima: Universidad Mayor de San Marcos, 1938. p. 20. 
Assim, Vitória deixaria, em definitivo, a órbita romana - que confundia o direito natural com o direito das gentes - e seria o primeiro a apresentar um conceito de jus gentium que corresponde ao de direito internacional contemporâneo. Ainda, para corroborar essa interpretação, a frase seguinte à passagem se inicia com Apud omnes enim nationes, o que permitiu de vez identificar as gentes de Francisco de Vitória com "nação", e não mais com "homens", como era no texto de Gaio.

\section{A defesa dos índios e o patriotismo espanhol}

No entanto, essa literatura produziu uma versão um tanto direcionada da obra de Vitória. Os autores dessa época procuravam um substituto para Hugo Grotius, então trataram de fazer o maestro espanhol falar mais do que havia sido a sua intenção. Uma leitura a partir das próprias premissas de Vitória, em vez dessa permeada por pré-concepções de outro tempo, revela um pensador preocupado em promover “[...] os valores especificamente cristãos e em justificar aquilo que os espanhóis chamam com franqueza de conquista". ${ }^{20}$

A estrutura mesma das Relecciones sobre os Indios mostra o propósito de Vitória. Na primeira relección, a primeira seção inteira busca demonstrar que os índios possuem suas terras de maneira válida. Essa demonstração, inobstante as profundas consequências jurídicas, serve a um propósito maior: comprovar que o infiel pode ter domínio. Professar outra religião que não a verdadeira não constitui motivo para despojar os hereges de seus bens. Posse, propriedade, domínio e soberania representam institutos independentes de religião. Com isso, o autor prepara-se para atacar a ideia de que o papa poderia exercer jurisdição sobre o mundo inteiro.

Essa lição cumpre o papel de introduzir a segunda seção. Nessa, Vitória procura refutar os títulos não legítimos pelos quais os espanhóis conquistaram os "bárbaros do Novo Mundo" (barbari novi orbis). São os títulos previstos no Requerimento de Burgos. O primeiro afirma que o imperador é senhor do mundo. Vitória não poderia

20 "[...] des valeurs spécifiquement chrétiennes et à justifier ce que les Espagnols appelaient sans ambages une conquête" HAGGENMACHER, Peter. 1492 Le choc de deux mondes. In: COMISSION NATIONALE SUISSE POUR L'UNESCO, Genève. Actes du Colloque... Genève: La Différence, 1993. p. 215. aceitar isso porque, de fato, não vivia mais num ambiente feudal. O imperador romano-germânico já ostentava um poder mais simbólico do que efetivo. Assim, Carlos V não poderia reivindicar as terras indígenas por sua própria autoridade. No segundo título, o autor rechaça o monismo pontifício. O papa não exerce jurisdição temporal em todo o orbe, porque Deus nunca fez essa doação. O terceiro título corresponde ao descobrimento. Todavia, aquelas terras não eram desprovidas de donos, por isso não há que se falar em nova aquisição. $\mathrm{O}$ quarto título refere-se à recusa dos índios em receber a fé de Cristo. Vitória não aceita este porque ele nega a legitimidade de todas as conversões forçadas. Pelo quinto título, os espanhóis poderiam declarar guerra aos índios por causa dos pecados deles; os quais atentariam não só contra a lei positiva divina, mas também contra a lei natural. Os índios comeriam carne humana e praticariam o incesto. Esse motivo é bastante grave, mas o papa não exerce jurisdição espiritual sobre os não convertidos e não poderia delegar a autoridade para corrigi-los. O sexto título corresponde à submissão voluntária dos índios aos espanhóis. Além do fato de que o medo e a ignorância viciam esse tipo de eleição, os hereges já têm soberano. Por fim, o último título conferiria aos espanhóis direitos sobre todos os bárbaros por uma doação especial de Deus. Vitória não se detém muito aqui porque esse argumento não se comprova nem pelas Escrituras, nem por milagre.

Até o momento, os escritos parecem fazer jus à imagem de Vitória como um santo humanista; entretanto, a relección prossegue. Na terceira seção, o autor passa a analisar os títulos legítimos pelos quais os espanhóis podem conquistar os bárbaros. O primeiro diz respeito à comunicação natural que subsiste em todo o mundo. Os espanhóis possuem o direito de visitar e de se estabelecer nas terras dos índios, sem sofrer dano algum. Se isso acontecer, será lícito guerrear. Desse título, deriva-se ainda a legitimidade do comércio, do uso das coisas comuns e da migração. Todos esses institutos pertenceriam ao direito das gentes, e um descumprimento constitui motivo de guerra justa. O segundo título refere-se à propagação da religião cristã. Os índios não são obrigados a se converterem, mas devem suportar a evangelização. Esse dever não é de direito das gentes, mas oriundo da verdadeira fé, e parece improvável que Vitória admitisse a reciprocidade. $\mathrm{O}$ terceiro e quarto título também correspondem à matéria de fé. Se alguns bárbaros se con- 
verterem, seus príncipes não podem empregar a força para volvê-los à idolatria, sob pena de uma guerra justa. E, após essa conversão ao cristianismo, o papa pode, com justa causa, conceder um príncipe cristão aos índios. O quinto título corresponde à tirania dos senhores bárbaros que promulgam leis inumanas com o sacrifício de inocentes. Trata-se do que se pode qualificar como o embrião de uma intervenção humanitária. No sexto, Vitória retoma a ideia de submissão voluntária ao rei da Espanha, mas ressalta que o consentimento deve ser válido. O sétimo título refere-se a alianças que algumas tribos podem fazer com os espanhóis contra outras. Nesse caso, é permitido prestar auxílio aos aliados. Por fim, se houver mesmo alguma comunidade incapaz de se governar, então, por caridade, os espanhóis podem conduzi-la. Contudo, devem fazê-lo não em proveito próprio, mas dos bárbaros.

Ainda, cabe acrescentar que toda a Segunda relectio sobre os indios versa sobre o próprio direito da guerra dos espanhóis sobre os bárbaroAssim, o dominicano faz regressar em novas bases tudo o que ele já havia refutado. $\mathrm{O}$ fato de os índios possuírem domínio não exclui a possibilidade de interdição. O papa pode não exercer jurisdição sobre eles, mas conta com um poder indireto. Os espanhóis podem lá se estabelecer, em virtude de uma sociedade natural de comunicação. Proíbe-se a conversão forçada, mas os índios devem suportar a evangelização. Práticas bárbaras, como sodomia e canibalismo, não justificam uma intervenção, mas essa pode ocorrer em defesa dos inocentes. Todas essas posições não se ajustam muito bem com a imagem de um defensor dos direitos dos indígenas.

Vitória era, com absoluta certeza, um homem de convicções. Não aceitava as teses oficiais do Requerimento para a conquista dos índios, nem a ideia de que o papa poderia exercer autoridade sobre todo o mundo, mesmo o não cristão. Mas era também tanto um patriota, como um defensor da fé cristã, ainda que a sua doutrina $\mathrm{o}$ afastasse dos argumentos corriqueiros de seu tempo. $\mathrm{O}$ patriotismo do autor era certamente diferente do ardor dos conquistadores: Vitória não queria terras, ele queria almas. Para Luciano Pereña, todo o direito da guerra da Segunda Escolástica é um verdadeiro "direito de intervenção". ${ }^{21}$ Como se verá a seguir, Vitória buscava a

\footnotetext{
${ }^{21}$ PEREÑA, Luciano. Estudio preliminar. In: SUÁREZ, Francisco. Guerra intervención paz internacional. Tradução para o castelhano de Luciano Pereña. Madrid: Espasa-Calpe, 1956. p. 10.
}

unidade espiritual do mundo por meio da religião cristã. E o único país europeu grande o suficiente, militarmente poderoso e católico o bastante, que poderia levar a cabo essa empreitada, era a Espanha. ${ }^{22}$ No debate entre Bartolomeu de Las Casas e Juan Ginés de Sepúlveda sobre o direito dos índios, Francisco de Vitória situava-se no meio.

\section{0 velho e o novo no totus orbis de vitória}

Mas o que dizer daquelas afirmações de Vitória que expressariam a ideia de uma sociedade internacional, que limita a soberania dos Estados e que se rege pelo direito? De fato, o teólogo de Salamanca menciona com frequência a expressão totus orbis ou mesmo a variante totus mundus. Não há dúvidas de que ela constitui um quadro referencial, mas causa estranheza o fato de o autor nunca a definir. Haggenmacher analisa, nas obras de Vitória, todas as passagens em que os termos aparecem. Em algumas vezes, eles possuem um sentido meramente factual e designam o "mundo inteiro", como uma realidade geográfica. Em outras mais raras, eles denotam uma entidade moral, investida de auctoritas ou potestas. Nessas, o totus orbis aparece como fonte ou do direito das gentes, ou somente do direito da guerra exercido a título de sanção pelos soberanos. ${ }^{23}$ Portanto, cumpre verificar se nessas ocasiões Vitória deseja introduzir uma noção original, assemelhada àquela de sociedade internacional.

22 'De fato, à primeira vista, a 'escola espanhola da paz' (termo empregado por Luciano Pereña) parece pouca espanhola e pouco católica. Contudo, a 'hispanidade' e a 'catolicidade' representam muito mais do que a mera defesa de uma política de Estado ou de uma concepção de mundo ultrapassada. O grande dilema do século XVI mostra-se a dissociação inexorável entre as duas cidades, a terrena e a de Deus. [...] A idéia de Império havia perdido lastro com os tempos históricos, e existiam tantas soberanias como o número de Estados. A Espanha [...] constituía a chave da crise e a última esperança de reconstrução da cristandade européia. Ela deveria converter-se no império a serviço da religião, da justiça e da civilização. Todos os príncipes católicos, por imperativo da fé, podiam proteger a Igreja. Mas somente um Estado grande e forte, como a Espanha, conseguiria se insurgir contra o cisma da terra e salvar a civilização cristã." MACEDO, Paulo Emílio Borges de. O nascimento do direito internacional. São Leopoldo: UNISINOS, 2009. p. 226.

${ }^{23}$ HAGGENMACHER, Peter. La place de Francisco de Vitoria parmi les fondateurs du droit international. TRUYOL y SERRA, Antonio et al. Actualité de la pensée juridique de Francisco de Vitoria. Bruxelles: Centre Charles De Visscher pour le droit international, 1988. p. 39. 
Em comentário ao Tratado da Justiça de Santo Tomás, Vitória analisa a questão 57 que considera o jus gentium um direito positivo, mas de origem natural. A obscuridade do pensamento do Aquinate sobre a natureza do direito das gentes terá reflexos na obra de Vitória: em determinados momentos, o jus gentium pertence ao direito natural, em outros, ao direito positivo. Nesse texto, o dominicano opta pelo último. Trata-se, contudo, de um direito positivo bastante singular em virtude da aparente ausência de legislador. Isso ocorre porque o direito positivo se manifesta de duas maneiras: pela condicta privata - que procede dos contratos ordinários entre particulares - e pela condicta publica - que se origina das convenções adotadas pelo conjunto de uma comunidade. ${ }^{24}$ Elas, normalmente, aparecem sob a forma de leis, o que garante a sua publicidade. Porém, quando se refere a um acordo entre todos os povos e nações do mundo inteiro, a publicidade é um elemento implícito. Segundo Haggenmacher, Vitória pretendia transpor uma distinção de direito civil para o direito das gentes. $\mathrm{O}$ aspecto público advém da universalidade da convenção. A linguagem do autor, portanto, mantém-se na esfera contratual, e o orbis não designa uma entidade autônoma e superior. A expressão corresponde tão-somente a um modo cômodo de se reportar à soma dos Estados. ${ }^{25}$ Portanto, nesse texto, apesar de aparentar uma fonte legislativa, o totus orbis não representa uma pessoa moral.

Entretanto, como explicar a passagem na Relectio de potestate civili, a já mencionada aliquo modo est una republica, na qual o totus orbis promulga verdadeiras leis? O trecho, em verdade, apresenta-se como um corolário da demonstração que o precede. Vitória questiona se as leis civis obrigam também os legisladores e os reis ("An leges civiles obligent legislatores et maxime reges?”). Essa pergunta justifica-se porque alguns acreditam que eles se encontram acima de toda a república e, por conseguinte, não haveria nenhum poder superior para constrangê-los. Segundo o teólogo de Salamanca, os soberanos também integram a república, e, como a lei é válida para toda a comunidade, eles também devem observá-la. Em relação

${ }^{24}$ VITÓRIA, Francisco de. De Jure Gentium et Naturali. In: SCOTT, J. B. The spanish origin of international law: Francisco de Vitoria and his law of nations. 2. ed. New Jersey: Law Book Exchange, 2003. p. 112.

${ }^{25}$ HAGGENMACHER, Peter. 1492 Le choc de deux mondes. In : COMISSION NATIONALE SUISSE POUR L'UNESCO, Genève. Actes du Colloque... Genève: La Différence, 1993. p. 41. aos soberanos, ocorre o que se passa com os contratos: antes de acordar, a pessoa é livre, mas, depois da convenção, ela se obriga. A seguir, Vitória infere o corolário: “[...] o direito das gentes não tem força apenas por causa do pacto e convenção dos homens, mas possui verdadeira força de lei. E o mundo todo, que de certo modo forma uma república, tem o poder de prescrever, a todos os súditos, leis justas, como são as de direito das gentes."26

Com essa afirmação, o autor deseja acentuar o caráter legal do direito das gentes. Contudo, isso não conflita com a natureza contratual acima exposta, pois a condicta publica possibilita essa equiparação com a lei. A ênfase deve-se a um raciocínio desenvolvido anteriormente. Vitória defende que a lei positiva, de modo diverso da lei natural, incide sobre ações que eram antes moralmente neutras. Mas, depois de editada uma lei positiva, a ação se torna proibida ou obrigada também pela lei natural. "Do que se depreende que pecam mortalmente todos os que violam os direitos das gentes". ${ }^{27} \mathrm{O}$ dominicano não procurou contrariar uma constatação anterior e alterar a origem convencional do jus gentium, mas ressaltar o argumento de que este direito também obriga em consciência.

Na Preleção sobre os índios, Vitória apresenta um duplo fundamento de validade ao direito das gentes: em algumas vezes, o direito natural, em outras, o consentimento humano. "Mas o que a razão natural estabeleceu entre todas as gentes se chama direito das gentes". Ou: "E uma vez que nem sempre se derive [o direito das gentes] do direito natural, parece que basta o consentimento da maior parte do mundo, sobretudo se é para o bem comum de todos." ${ }^{28}$ (grifo nosso). É revelador o fato de

26 "Quod ius gentium non solum habet vim ex pacto et condicto inter homines, sed etiam habet vim legis. Habet enim totus orbis, qui aliquo modo est una republica, potestatem ferendi leges aequas et convenientes omnibus, quale sunt in iure gentium." VITORIA, Francisco de. Obras de Francisco de Vitória: relecciones teologicas. Madrid: Biblioteca de Autores Cristianos, 1960. p. 191.

27 "Ex quo patet quod mortaliter peccant violantes iura gentium." VITORIA, Francisco de. Obras de Francisco de Vitória: relecciones teologicas. Madrid: Biblioteca de Autores Cristianos, 1960. p. 191.

28 "Quod naturalis ratio inter omnes gentes constituit, vocatur ius gentium" e "Et dato quod non semper derivetur ex iure naturali, satis videtur esse consensus maioris partis totius orbis, maxime pro bono communi omnium." VITORIA, Francisco de. Obras de Francisco de Vitória: relecciones teologicas. Madrid: Biblioteca de Autores Cristianos, 1960. p. 710. 
Vitória ter pronunciado essa lição um decênio após a anterior. Se o dominicano decidiu debruçar-se sobre a natureza do jus gentium, mudou de opinião com os anos; de positivo, o direito das gentes passou a pertencer parte ao direito natural e parte ao direito positivo. Ou, ainda, resta a alternativa de que ele nunca haveria se preocupado com o jus gentium, e esse duplo fundamento denota a sua indiferença à questão. Em ambas as possibilidades, Vitória afasta-se de uma concepção mais contemporânea de direito internacional.

Perceba-se que, neste último excerto, o jus gentium não retira a sua validade do totus orbis, mas da maioris partis totius orbis. A alteração - sem dúvida - resulta do alargamento do campo de visão que a descoberta dos "bárbaros do Novo Mundo" proporcionou. Isso produz consequências bastante interessantes. $\mathrm{O}$ consentimento da maioria da humanidade pode impor-se sobre o mundo inteiro, mesmo contra a vontade de uma minoria (que não é tão esclarecida).

É nessa imposição que se baseia a legitimidade da guerra que os europeus podem travar contra os índios, abordada na segunda preleção sobre os índios. Os príncipes exercem autoridade não só sobre seus súditos, mas também sobre estrangeiros para impedi-los de cometer erros. E esse poder decorre da autoridade de todo o or$b e .^{29}$ Além da defesa do colonialismo espanhol, para o presente propósito, deve extrair-se outra consequência. Nas duas lições sobre os índios, o orbe parece mesmo constituir uma fonte legislativa, por vezes de todo o jus gentium, por vezes apenas do poder vindicativo dos soberanos.

No entanto, salienta Haggenmacher que, em nenhum momento, Vitória investiga a figura do orbe em si. Ela aparece sempre em relação a outros problemas (o direito das gentes e o poder vindicativo) e nunca como o centro da discussão. Por essa razão, o seu conceito resta indeterminado. Por conseguinte, nas raras ocasiões em que o totus orbis se apresenta como um todo orgânico, superior à soma dos Estados, o autor não poderia estar referindo-se a uma realidade nova, a qual deveria deman-

${ }^{29}$ VITÓRIA, Francisco de. De Jure Belli. 2. SCOTT, J. B. The spanish origin of international law: Francisco de Vitoria and his law of nations. 2. ed. New Jersey: The Law Book Exchange, 2003. Cabe observar que, aqui, essa norma de direito das gentes se funda no direito natural. dar uma análise mais detida. Trata-se, portanto, de algo bastante velho, que dispensa apresentações e, por isso, provavelmente se perde num passado imemorial: o orbis christianus. ${ }^{30}$ A Respublica Christiana correspondia a um quadro de referências antigo, que todo europeu conhecia. $\mathrm{O}$ totus orbis consiste numa abstração marginal dessa concepção, que já havia deixado de ser uma experiência. Significa uma atualização de uma realidade pretérita (ainda não esquecida de todo) por causa da descoberta de povos não cristãos no Novo Mundo, mas que, de uma forma ou de outra, terminaram por se encontrar sob a jurisdição de povos cristãos.

A distinção entre cristãos e não cristãos revela-se essencial para a compreensão do direito das gentes de Vitória. Assim como o jus gentium romano regia as relações entre romanos e estrangeiros, o jus gentium do teólogo de Salamanca governa as relações entre cristãos e não cristãos. E, tal como aquele não guardava semelhança com o direito internacional contemporâneo, porque se aplicava no interior do Império Romano, este incide dentro de um império europeu alargado pelas Grandes Descobertas. Trata-se do direito interno de uma comunidade multirreligiosa, mas de jurisdição cristã.

As teses e ilustrações de Vitória foram pensadas em função do orbis christianus. O que ele fez foi derivar as consequências para toda a humanidade. Assim, da mesma maneira que cada província cristã integra a cristandade europeia, cada república faz parte do orbe. E o exemplo que o autor utiliza na lição sobre a potestade civil, para comprovar que cada Estado possui uma ligação orgânica com o mundo inteiro, mostra-se bastante sugestivo. Afirma Vitória que um Estado, mesmo que possua uma causa justa, não deverá entrar em guerra se ela prejudicar o totus orbis. E "[...] se a guerra fosse dos espanhóis contra os franceses, mesmo que haja motivos justos e vantagem para a Espanha, caso a guerra cause maior dano e fratura para a cristandade, com o risco dos turcos ocuparem as províncias cristãs, deverá desistir-se

\footnotetext{
${ }^{30}$ HAGGENMACHER, Peter. 1492 Le choc de deux mondes. In : COMISSION NATIONALE SUISSE POUR LUNESCO, Genève. Actes du Colloque... Genève: La Différence, 1993. p. 45-46.
} 
dessa guerra". ${ }^{31}$ A ilustração do autor não se refere ao totus orbis, tão-somente à Respublica Christiana.

Consoante Haggenmacher, o teólogo de Salamanca escolheu um exemplo que iria, com toda a certeza, convencer seus expectadores, porque apelava para um receio geral que pairava sobre a atualidade política; porém, ele se ajusta mal ao conjunto do orbe, visto que era, como ainda é, uma perspectiva muito remota o mundo inteiro se tornar cristão. À época de Vitória, imaginar que o totus orbis poderia formar uma república só poderia ser aliquo modo. Trata-se de uma noção longínqua e impalpável, que foi evocada apenas para servir de explicação para certas regras de fundo; essas sim centrais ao raciocínio. Diversa é a situação no seio da cristandade, na qual Vitória poderia conceber sem qualquer dificuldade uma monarquia universal. ${ }^{32}$

\section{0 direito das gentes de vitória}

E o que afirmar da modificação que o teólogo de Salamanca teria realizado na definição de jus gentium de Gaio (Quod naturalis ratio inter omnes gentes constituit, vocatur ius gentium)? Se essa alteração foi intencional, Vitória desejava mostrar que o sujeito do direito das gentes consiste nos Estados, não nos indivíduos. No entanto, mesmo sem analisar o conceito de Estado para Vitória, é possível demonstrar que essa questão nunca se apresentou ao autor.

Quando o dominicano indaga se os índios, antes da chegada dos espanhóis, possuíam a propriedade pública e privada de suas terras, ele não investiga a personalidade jurídica internacional dos índios, mas simplesmente a personalidade jurídica. Porque, em caso afirmativo, os conquistadores não poderiam despojá-los de seus bens, e as teses do Requerimento de Burgos não se aplicariam. As atenções de Vitória não se voltam a uma suposta diferença entre propriedade pública e privada, mas à capacidade

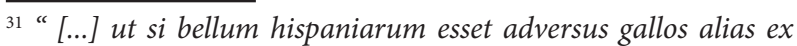
causis iustis susceptum et alioqui regno hispaniarum utile, tamen cum maiore malo et iactura geritur christianitatis, puta qui turcae occupant interim provincias christianorum, cessandum esset a tali bello." VITORIA, Francisco de. Obras de Francisco de Vitória: relecciones teologicas. Madrid: Biblioteca de Autores Cristianos, 1960. p. 168.

${ }^{32}$ HAGGENMACHER, Peter. 1492 Le choc de deux mondes. In : COMISSION NATIONALE SUISSE POUR L'UNESCO, Genève. Actes du Colloque... Genève: La Différence, 1993. p. 46. jurídica dos índios. Ele não busca comprovar o caráter estatal das comunidades dos bárbaros do Novo Mundo, e sim a natureza plenamente humana dos indivíduos que a compõem. E, adiante, quando o autor trata dos títulos válidos de intervenção, o foco constitui sempre a barbárie ou a infidelidade dos indivíduos. Vitória procura por almas para converter e salvar. ${ }^{33}$

O teólogo de Salamanca se ocupa de homens, não de Estados; até porque ele confunde o direito das gentes com o direito natural. A referência a Gaio encontra-se inserida no primeiro dos quatorze argumentos que visam demonstrar que os espanhóis podem visitar os índios. $\mathrm{Na}$ própria definição, o jus gentium decorre da razão natural. E o raciocínio inicia-se com “[...] prova-se, em primeiro lugar, pelo direito das gentes, que é direito natural ou dele derivado" ${ }^{34}$ Em oposição a sua tese anterior - segundo a qual o jus gentium procede de um acordo tácito -, Vitória aqui estabelece um fundamento natural. E não havia como isso ser diferente. Não existe nada em comum entre espanhóis e índios, salvo a própria natureza.

Dessa feita, na definição de Gaio, Vitória não deseja sublinhar o inter omnes gentes, mas a naturalis ratio. Então por que o autor substituiu homines por gentes? No trecho inteiro - reproduzido acima -, apesar de mencionar homines, o jurista de Justiniano também fala em populi e gentes, e é a sua presença que pode explicar a origem etimológica da expressão jus gentium. Vitória, pois, tentou invocar a fórmula de Gaio, que ele cita de forma aproximada. Para o dominicano, inter omnes gentes não difere de inter omnes homines. A continuação de um, apud omnes enim nationes habetur inhumanum, faz eco diretamente a do outro, apud omnes populos peraeque custoditur. Vitória, portanto, quis evocar a concepção romana de jus gentium, um direito interno comum com fundamento numa espécie de necessidade natural intrínseca.

Cumpre salientar que a escolha do termo nationes não se mostra de todo fortuita. Vitória parece lembrar-se da definição de direito natural de Santo Isidoro de Sevilha: “[...] o direito natural é comum a todas as nações e

\footnotetext{
${ }^{33}$ HAGGENMACHER, Peter. La place de Francisco de Vitoria parmi les fondateurs du droit international. New Jersey : Law Book Exchange, 2003. p. 50-56.

34 "Probatur primo ex iure gentium, quod vel est ius naturale, vel derivatur ex iure naturale" VITORIA, Francisco de. Obras de Francisco de Vitória: relecciones teologicas. Madrid: Biblioteca de Autores Cristianos, 1960 p. 706.
} 
provém de um instinto natural". ${ }^{35}$ Conforme a vocação de sua obra, Isidoro produz um jogo etimológico que pode passar despercebido por um leitor moderno. Já que o direito natural se aplica a todas as nações e se origina de um instinto natural, deve existir algo em comum a todas essas palavras: a raiz comum, o verbo nasci. O direito natural constitui, pois, um direito "de nascimento", que "nasce" junto com o homem, e não por uma convenção legislativa. Vitória, que por dever de ofício conhecia as Etimologias, quis discretamente insinuar essa conotação e inseriu a palavra nação para fazer correspondência ao ius naturale mencionado no início da passagem como fonte direta ou indireta do seu ius gentium. ${ }^{36}$

Não restam dúvidas de que aqui o autor concentra os seus esforços para conferir um fundamento ao direito das gentes. Mas ele repousa na natureza, o que o distinguiria do direito internacional. E revela-se curioso que o primeiro Vitória - que embasa o seu jus gentium numa convenção - não parece tão preocupado com a fundamentação: "[...] primeiro, a disputa diz respeito mais ao nome do que à coisa, porque importa pouco se alguém afirma isso [a pertença do direito das gentes ao direito positivo] ou aquilo [a pertença do ramo ao direito naturall]". ${ }^{37}$ Quando Vitória se preocupa com o fundamento de validade, ele decorre da natureza; quando ele considera a questão de somenos importância, a origem é de direito positivo.

Assim, o teólogo de Salamanca não consegue ultrapassar a concepção romana de jus gentium. Esse ainda é um direito interno de um império, comum a diferentes povos (mas não entre esses povos) e que, por vezes, confunde-se com o natural. Entretanto, de modo bastante paradoxal, a fraqueza dos argumentos de Vitória sobre o direito das gentes constitui a força de seu legado. Ainda que nunca houvesse concebido um direito entre socieda-

35 "Ius naturale commune omnium nationum, et quod ubique instinctu naturae" ISIDORUS HISPALENSIS EPISCOPUS. Etymologiarum sive originum libri XX. Oxford: Claredon Press, 1911.p. 5.

${ }^{36}$ HAGGENMACHER, Peter. La place de Francisco de Vitoria parmi les fondateurs du droit international. New Jersey : Law Book Exchange, 2003 p. 61.

37 "[...] first of all the dispute concerns the name more than the thing, for it matters little whether one says this or that" VITÓRIA, Francisco de. De Jure Gentium et Naturali. In: SCOTT, J. B. The spanish origin of international law: Francisco de Vitoria and his law of nations. 2. ed. New Jersey: The Law Book Exchange, 2003. p. 111. des políticas, o dominicano, de fato, substituiu homines por gentes. Embora nunca tivesse conferido um fundamento muito claro ao direito das gentes, em determinado momento, ele o considerou parte do direito positivo. Não obstante ter defendido o direito de intervenção dos espanhóis sobre os índios, ele concedeu aos "bárbaros do Novo Mundo" a possibilidade de domínio. E mesmo que o totus orbis não passasse de uma abstração inconsequente, a expressão foi empregada de forma recorrente. Vitória estabeleceu as bases para que outra pessoa que o lesse pudesse discorrer sobre um direito entre os povos, de natureza positiva, inserto numa sociedade internacional que se sobrepõe à soberania estatal.

\section{Conclusão}

A década de 1860 marca a virada para os estudos de Vitória por causa de um fato bastante inusitado: a descoberta do De Jure Praedae Commentarius, obra que Hugo Grotius jamais publicou e que havia desaparecido. Mas em vez de chamar as atenções para o jurista holandês, as diversas referências aos escolásticos, em especial ao teólogo de Salamanca, serviram de argumentos à disputa da paternidade do direito das gentes. Já no início do século XX, a reputação de Francisco de Vitória encontrava-se bastante consolidada, e nenhum estudo de história do direito internacional podia omiti-lo. O teólogo dominicano deixa de figurar entre os precursores de Grotius e passa a protagonizar monografias inteiras, como a de Quilicus Albertini. Ademais, estudos como o de Alfred Vanderpol e de Joseph Kohler tratam de enaltecer a versão católica do direito natural e das gentes. Os protestantes haviam perdido a batalha. ${ }^{38}$

Poucos anos depois, as vozes esparsas se tornam um coro ruidoso. Em 1927, na Academia de Direito Internacional da Haia, um discípulo de Ernst Nys, Camilo Barcia Trelles ministra um curso sobre Francisco de Vitória. No mesmo ano, surgem as lições ministradas na Espanha por um autor protestante e anglo-saxão, James Brown Scott. A Origem Hispânica do Direito Internacional consiste na primeira versão de uma obra que seria diversas vezes revisada e publicada. O nome do teólogo de

\footnotetext{
${ }^{38}$ HAGGENMACHER, Peter. La place de Francisco de Vitoria parmi les fondateurs du droit international. New Jersey : Law Book Exchange, 2003. p. 32-33.
} 
Salamanca espalhou-se por todos os locais. Em França, vários trabalhos sobre direito público - como os de $\mathrm{Hu}$ bert Beuve-Méry, Jean Baumel e a clássica obra de Joseph Delos - mencionam-no em posição de destaque. Na Alemanha dos anos de 1930, Friedrich Heydte, Heinz Kipp e Alois Dempf dedicam muito mais atenção ao teólogo espanhol do que Carl von Kaltenborn havia feito em 1848. ${ }^{39}$ Em 1926, na Espanha mesmo, é fundada a Associação Francisco de Vitória, renomeada, em 1933, para Instituto de Direito Internacional Francisco de Vitória. Enfim, pouco antes da II Guerra Mundial, a Sala dos Conselhos do Palácio das Nações, depois de decorada por José María Sert, é batizada Sala Francisco-de-Vitória.

O prestígio do teólogo dominicano cresce tanto que ele conquista autonomia dos demais membros da Escolástica Espanhola. Enquanto alguns autores advogam a existência de uma verdadeira escola hispânica de direito internacional, outros procuram destacar Vitória do restante. ${ }^{40}$ Em seu livro sobre os princípios do direito público, Delos compara Vitória e Suárez, sempre em detrimento deste último, para mostrar que a concepção de sociedade internacional de Vitória possuiria um fundamento objetivo, enquanto que aquela do jurista de

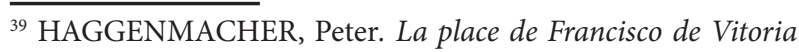
parmi les fondateurs du droit international. New Jersey : Law Book Exchange, 2003. p. 34-35.

${ }^{40}$ Entre os que negam a existência de uma escola espanhola de direito internacional encontram-se BARCIA TRELLES, Camilo. Francisco Suárez: les théologiens espagnols du XVI e siècle et lécole moderne du droit international. Recueil de cours de l'Académie de Droit International de Le Hague, Haia, v.3,n. 1, p. 386-503, 1933 e DELOS, J. T. La société internationale et les principes de droit public. 2. ed. Paris: Pédone, 1950. Entre os que defendem essa ideia estão Adolfo Miaja de la Muela (Internacionalistas Españoles del Siglo XVI. Fernando Vasquez de Menchaca. Valladolid: Universidad de Valladolid, Sección de Estudios Americanistas, 1932) e Luciano Pereña. Este último, embora acredite em um verdadeiro corpus hispanorum de pace, dedica boa parte de suas obras a estudar Suárez, em especial. Os trabalhos desse autor estão referidos nos capítulos II e IV. Ainda está por merecer um estudo sério se os que vêem discordâncias tão aberrantes entre os trabalhos de natureza jurídica de Francisco de Vitória e os dos demais escolásticos espanhóis, sobretudo Francisco Suárez, não refletem apenas a rusga de origem teológica que os dominicanos (Bañez) travaram com os jesuítas (Molina) sobre o problema da pré-ciência de Deus.
Coimbra denotaria um voluntarismo estatalista - logo, ele seria um precursor do positivismo jurídico. ${ }^{41}$

As preleções de Vitória apresentam uma estética que agradou muito a sensibilidade de uma literatura a qual buscava um novo pai para a disciplina de direito internacional. Em uma bela imagem, James Brown Scott considera Francisco de Vitória o expositor inicial, Francisco Suárez, o filósofo, e Hugo Grotius, o sistematizador. ${ }^{42}$ Mas esa literatura promoveu uma leitura enviesada do teólogo de Salamanca: selecionou alguns trabalhos, ignorou outros, e, assim, disseminou uma concepção de Vitória que se ajustava aos seus propósitos revisionistas, mas retirava o autor do seu próprio tempo.

O debate sobre o primeiro fundador mostra-se, contudo, insolvível. Qualquer trabalho que defenda um nome em detrimento de outro será ideológico: de posse daquilo que consideram a "quintessência" do direito internacional (em geral, ou o direito positivo, ou o "estatalismo"), os historiadores de outro tempo procuram encontrar vestígios desses elementos na doutrina de autores dos séculos XVI e XVII. Faz-se necessário lembrar que Vitória, Suárez, Gentili e Grotius escreviam para um público diferente e possuíam preocupações bem distintas.

A ideia, no entanto, de um pai único para todo o direito internacional só seria enterrada com a publicação, em 1904, da obra coletiva de Antoine Pillet: Les fondateurs du droit international, composta por uma série de ensaios, e cada qual versa sobre um fundador. O título já denota a mudança de perspectiva; em vez de um pai, a disciplina comportaria diversos fundadores. A mesma ótica perpassa a coleção Classics of International Law, lançada em 1906 pelo Carnegie Endowment for International Peace, sob a iniciativa de James Brown Scott. O internacionalista bel-

\footnotetext{
${ }_{41}$ "Or, à ce problème, il n'y a en définitive, que deux solutions: la force obligatoire du droit positif lui vient d'un fondament objectivf, le bien commun, dont il interprète les exigences idéales en fonction d'un donné historique, - ou de l'accord de volontés. Volontarisme ou droit à fondement objectif, telles nous semblent les seules branches de l'alternative. On pressent en quel sens se prononcera Suarez." DELOS, J. T. La société internationale et les principes de droit public. 2. ed. Paris: Pédone, 1950. p. 270.

${ }^{42}$ Ainda assim, o epíteto de filósofo não impede Scott de subtrair toda a originalidade de Suárez: a famosa distinção suareziana de jus intra gentes e jus inter gentes já se encontraria em Vitória, bem como a descrição deste da comunidade internacional apresentar-se-ia mais bela e completa. SCOTT, J. B. The catholic conception of International Law. Washington D.C.: Georgetown University Press, 1934. p. 183-184.
} 
ga Maurice Bourquin, numa conferência em Genebra, em 1946, resumiu bem essa nova posição: “O pai do direito das gentes é uma sociedade em nome coletivo, se ouso assim me exprimir; é uma série de pensadores e juristas, os quais uns precederam Grotius e outros engrandeceram e desenvolveram sua obra durante os séculos XVII e XVIII." ${ }^{43}$

\section{Referências}

BARCIA TRELLES, Camilo. Francisco Suárez: les théologiens espagnols du XVI e siècle et l'école moderne du droit international. Recueil de Cours de l'Académie de Droit International de Le Hague, Haia, n. 1, p. 386-503, 1933.

BARTHÉLEMY, Joseph. François de Vitoria. In : PILLET, Antoine. Les fondateurs du droit international. Paris: V. Giard \& E. Brière, 1904.

BORGES DE MACEDO, Paulo Emílio. O nascimento do direito internacional. São Leopoldo: UNISINOS, 2009.

BOURQUIN, Maurice. Grotius est-il le père du droit des gens? (1583-1645). In:__ Grandes figures et grandes oeuvres juridiques. Genève: Librairie de l'Université, Georg \& Cie., 1948.

DELOS, J. T. La société internationale et les principes de droit public. 2. ed. Paris: Pédone, 1950.

GROTIUS, Hugonis. De jure praedae commentarius. La Haye: Hamaker, Nijhoff, 1868.

HAGGENMACHER, Peter. 1492 le choc de deux mondes. In : COMISSION NATIONALE SUISSE POUR L'UNESCO, Genève. Actes du Colloque. Genève: La Différence, 1993. pp. 210-222.

HINOJOSA, Eduardo. Influencia que tuvieron en el derecho público de su pátria y singularmente en el derecho penal los filósofos y teólogos españoles, anteriores a nuestro siglo. Madrid: Reus, 1890.

HOLLAND, Thomas E. Alberico Gentili: an inaugural lecture delivered at all souls college. In: STUDIES IN INTERNATIONAL LAW, 7., 1874, Oxford: Clarendom Press, 1898.

${ }_{43}$ "Le père du droit de gens, c'est une société en nom collectif, si jose ainsi mexprimer; c'est une série de penseurs et de juristes, dont les uns on précédé Grotius, dont les autres on élargi et développé son oeuvre, au cours du XVIIème et du XVIIIème siècles." BOURQUIN, Maurice. Grotius est-il le père du droit des gens? (1583-1645). In: Grandes figures et grandes oeuvres juridiques. Genève: Librairie de l’Université, 1948. p. 77.
ISIDORUS HISPALENSIS EPISCOPUS. Etymologiarum sive originum libri XX. Oxford: Claredon Press, 1911.

IUSTINIANUS IMPERATOR. Corpus iuris civilis. Berlim: Weidmann, 1908.

MIAJA DE LA MUELA, A. Internacionalistas españoles del siglo XVI. Fernando Vazquez de Menchaca. Valladolid: Universidad de Valladolid, 1932.

NYS, Ernest. Le droit de la guerre et les précurseurs de Grotius. Bruxelles et Leipzig: Murquardt, 1882.

RIVIER, Alphonse. Note sur la littérature du droit de gens avant la publication du Jus Belli ac Pacis de Grotius (1625). Bruxelles: Académie Royale de Belgique, 1883.

SCOTT, J. B. Conferencias del presidente del Instituto Americano de Derecho Internacional preparadas en homenaje a la Universidad Mayor de San Marcos. Lima: Universidad Mayor de San Marcos, 1938.

SCOTT, J. B. The catholic conception of International Law. Washington D.C.: Georgetown University Press, 1934.

SCOTT, J. B. The spanish origin of international law: Francisco de Vitoria and his law of nations. 2. ed. New Jersey: The Law Book Exchange, 2003.

STUMPF, Christoph A. Christian and islamic traditions of public international law. Journal of the History of International Law, Hamburgo, n. 7, p. 68-80, abr. 2005.

SUÁREZ, Francisco. Guerra intervención paz internacional. Tradução para o castelhano de Luciano Pereña. Madrid: Espasa-Calpe, 1956.

TIERNEY, Brian. Vitoria and suarez on ius gentium, natural law and custom. In: - The nature of customaryl: philosophical, historical and legal perspectives. Cambridge: University of Cambridge, 2004.

TRUYOL y SERRA, Antonio et al. Actualité de la pensée juridique de Francisco de Vitoria. Bruxelles: Bruylant, Centre Charles De Visscher pour le droit international, 1988.

VIEJO-XIMÉNEZ, José Miguel. Totus orbis, qui aliquo modo est una republica: Francisco de Vitoria, el derecho de gentes y la expansión atlántica castellana. Revista de Estudios Histórico-Jurídico: sección historia del pensamiento jurídico, Valparaíso, n. 26, p. 359-391, 2004.

VITORIA, Francisco de. Obras de Francisco de Vitória: relecciones teologicas. Madrid: Biblioteca de Autores Cristianos, 1960.

WATTS, Alan W. Myth and ritual in christianity. London: Thames and Hudson, 1953. 
Para publicar na Revista de Direito Internacional, acesse 0 endereço eletrônico www.publicacoesacademicas.uniceub.br. Observe as normas de publicação, para facilitar e agilizar o trabalho de edição. 